ISSN 0258-7122

Bangladesh J. Agril. Res. 36(1) : 21-28, March 2011

\title{
GENETIC DIVERSITY OF SOME RESTORER LINES FOR HYBRID RICE DEVELOPMENT
}

\author{
M. U. KULSUM ${ }^{1}$, M. J. HASAN ${ }^{2}$, H. BEGUM ${ }^{3}$ \\ M. M. BILLAH ${ }^{4}$ AND H. RAHMAN ${ }^{5}$
}

\begin{abstract}
Genetic divergence of thirty six restorer lines was studied through Mohalanobis's $\mathrm{D}^{2}$ and principal component analysis for nine characters. Genotypes were grouped into five different clusters. Cluster III comprised of maximum number of genotypes (eleven) followed by cluster I and IV. The intercluster distance was maximum between clusters II and IV (14.064) indicating wide genetic diversity between these two clusters followed by the distance between cluster II and V (10.353), cluster III and cluster IV (8.588). The minimum inter- cluster distance was observed between cluster I and cluster III (2.885) followed by cluster I and cluster V (4.359) and cluster III and cluster V (4.825) indicating that the genotypes of these clusters were genetically close. The intra cluster distance in the entire five clusters was less, which indicated that the genotypes within the same cluster were closely related. Among the characters, number of tillers/hill, panicle length, number of filled spikelets/ panicle, spikelet fertility \% and yield/plant contributed most for divergence in the studied genotypes. It indicates that these parameters can contribute more for yield in hybrid rice development.
\end{abstract}

Keywords: Rice, restorer line, genetic divergence, $\mathrm{D}^{2}$.

\section{Introduction}

Rice is considered as a major crop in Bangladesh as it constitutes $7.5 \%$ of the total food grain (rice and wheat) production of 38.06 million metric tons (Anonyrnous, 2009). Rice is the staple food and ranks first in production among cereals in Bangladesh. Although Bangladesh is now on the verge of attaining self sufficiency in cereal production, there is still a large gap between the production and demand. We need to produce more rice per unit area per unit time. Achieving self-sufficiency in rice production and maintaining price stability are important political objectives in countries where rice provides food security and generates employment and income for people (Hossain. 1995). Yuan (2001) reported that more than $50 \%$ of rice area in China is covered by hybrid rice. Expansion of hybrid rice cultivation area may be an effective and economic way to meet the future rice demands of growing population of Bangladesh.

\footnotetext{
${ }^{1,2 \& 5}$ Hybrid Rice Project, ${ }^{3}$ GRSD, Bangladesh Rice Research Institute (BRRI), Gazipur 1701, ${ }^{4}$ Scientific Officer, Plant Breeding Division, Bangladesh Agricultural Research Institute (BARI), Gazipur 1701. Bangladesh.
} 
Hybrid rice technology offers considerable opportunity for Bangladesh to increase the productivity. One of the limitations of this technology, however, is the need for cultivators to secure new seeds every season. Use of rice hybrids is getting popular in Bangladesh day by day. It was started in 1998 with few tons and in the year 2008, the quantity of seed rises to 11000 tons of which 2800 tons are locally produced (Anwer Faruque, 2009). The performance and heterosis of hybrids are associated with genetic divergence between their parental lines. The selection of parental lines plays a vital role in developing ideal combinations. Study of diverse genotypes of a crop is necessary to evaluate their performances which help develop a new variety suitable for commercial cultivation. Grouping or classification of genotypes based on suitable scale is quite imperative to understand the usable variability existing among them. Selection of suitable parental (CMS/maintainer and restorer) lines to develop heterotic combinations can be facilitated by determining genetic divergence among them. Very limited work has been done on analysis of the genetic divergence in rice in relation to hybrid rice breeding. Careful selection of maintainer and restorer lines on the basis of their genetic diversity may lead to the development of hybrids with higher yield potential than parents and standard check varieties (Julfiquar et al., 1985). Hybrid rice is considered as a viable alternative technology for breaking the present yield ceiling of modern varieties. In China and India, hybrid rice provides an yield advantage of 1.0-1.5 t/ha (20-30\%) over the conventional inbred varieties (Virmani, 1994). Seventy two (72) hybrid rice varieties were so far released from National Seed Board (NSB) under various private companies and public organizations. All of them belong to three-line system. Three line systems involve three component lines that is CMS line (A line), maintainer line (B line), and restorer line ( $\mathrm{R}$ line).Thus keeping in view the above facts, present study was conducted to estimate the nature and magnitude of genetic divergence and characters contributing to the genetic divergence of thirty six restorer lines ( $\mathrm{R}$ lines). This study will help in selection of more distantly related restorer lines for using in crossing programme and ultimately help develop high yielding hybrid rice varieties in local conditions.

\section{Materials and Method}

Thirty six restorer lines were grown in a randomized complete block design with three replications at the experimental farm of Bangladesh Rice Research Institute. Gazipur, during Boro season 2007-2008. The experimental site was at $24.00^{\circ} \mathrm{N}$ latitude and $90.25^{\circ} \mathrm{E}$ longitude with an elevation of 8.4 meter from the sea level. The whole experimental area was divided into three blocks, representing three replications. Adequate soil fertility was ensured by applying additional quantities of Urea- TSP-MP- Gypsum- ZnSO ${ }_{4} @$ 270:130:120:70:10 $\mathrm{kg} / \mathrm{ha}$, respectively. Total TSP, MP, Gypsum, and $\mathrm{ZnSO}_{4}$ were applied in final land preparation. Total Urea was applied in three installments at 15 days after 
transplanting (DAT), 30 DAT, and 45 DAT. Thirty (30) days old seedlings of restorer lines were transplanted in separate strips with the spacing of $15 \times 15 \mathrm{~cm}$ between plant to plant and $20 \times 20 \mathrm{~cm}$ between row to row. Necessary intercultural operation was made during cropping period for proper growth and development of the plants. Data were collected from 10 randomly selected hills of each restorer line on individual plant basis for number of effective tillers per hill, days to $50 \%$ flowering, days to maturity, plant height, panicle length, number of filled grains per panicles, spikelet fertility \%, 1000-grain weight, and grain yield per plant. Mean data of each character was subjected to multivariate analysis viz. Principal Coordinate Analysis (PCO), Principal Component Analysis (PCA), Cluster Analysis, and Canonical Variate Analysis using GENSTAT 513 (Mahalanobis, 1936; Digby et al., 1989 and Jager et al., 1983).

\section{Results and Discussion}

The analysis from distance matrix gave non-hierarchical clustering among 36 restorer lines and grouped them into five clusters (Table I). Cluster III contained the highest number of restorer lines (eleven), followed by cluster I and cluster IV constituted by eight restorer lines. Cluster $\mathrm{V}$ was composed of only two genotypes. Cluster II composed of seven genotypes, cluster V composed of eight restorer lines.

Table 1. Distribution of 36 restorer lines in different clusters grown in Boro season 2007-2008.

\begin{tabular}{|c|c|c|c|}
\hline Cluster no. & $\begin{array}{c}\text { No. of } \\
\text { genotypes }\end{array}$ & $\begin{array}{c}\text { No. of } \\
\text { populations }\end{array}$ & Restorer lines \\
\hline $\mathrm{I}$ & $\begin{array}{l}1,5,6,9,13 \\
16,31,34\end{array}$ & 8 & $\begin{array}{l}\text { BR827R, PSBRC82R, 1R6801I-15-1-1-2- } \\
\text { 3R, IR64R, Gui99R, Wan3R, BR6839-41- } \\
\text { 5-IR, HP-2 }\end{array}$ \\
\hline II & $\begin{array}{l}\text { 4, 7,8,10, - } \\
12,18.23,\end{array}$ & 7 & $\begin{array}{l}\text { IR7320-44-2-3-IR, 1R73004-107-3-3-2R, } \\
\text { IR73004-7-3-3-3R, 1R71137-328-2-3-3- } \\
\text { 2R, IR697 16-37-1-I -5-IR, 1R54742R, } \\
\text { 1R44675R }\end{array}$ \\
\hline III & $\begin{array}{l}11,14,15 \\
17,22,27 \\
28,29,32 \\
33,36\end{array}$ & 11 & $\begin{array}{l}\text { IR73885-1-4-I-4-4-3-6R, M.H.63R, } \\
\text { M.H.77R, IR40750R, 1R73013-95-1-3-2R, } \\
\text { 1R72887-38-l-3-2R, 1R69701-4 1-3-JR. } \\
\text { 1R69702-3-2-3R, IR73944-3-2-3-2- } \\
\text { 2R,_HP-I, HP-4 }\end{array}$ \\
\hline IV & $\begin{array}{l}2,3,19.20 . \\
21,24,30,35\end{array}$ & & $\begin{array}{l}\text { BRI68R, BR736R, lR55838-B2-2-3-3R, } \\
\text { AjayaR, IR46R, BRRIIOR, BR6723-1-1- } \\
\text { 2R, HP-3 }\end{array}$ \\
\hline $\mathrm{V}$ & 25,26 & 2 & IR32809-26-3-3R, IR72906-24-1-3-IR \\
\hline
\end{tabular}


Among them, BRRI IOR is locally developed. Grouping of all the genotypes from different sources indicated that there is no association between clustering pattern and ceo-geographical distribution of the genotypes. On the other hand, Singh et al. (1979), Singh (1981), Dc and Rao (1987) and Singh et al. (1987) revealed that geographical diversity is not necessarily related to genetic diversity. Intra and inter cluster distances are presented in Table 2. The inter cluster distances in almost all of the cases was larger than the intra cluster distances indicating that wider diversity was present among genotypes of distance groups. The intra-cluster distances were low for all the five clusters with the range of 0.182 in cluster I to 0.268 in cluster II which indicated homogeneous nature of the genotypes within the clusters. These results were supported by the findings of lftekharuddaula et al. (2002) in rice.

The $\mathrm{D}^{2}$ values ranged from 2.885 to 14.064 and PCA scores also indicated a high degree of genetic diversity among the genotypes. Regarding inter cluster distance, clusters II and IV showed maximum genetic distance (14.064) from these two clusters followed by the distance between cluster II and cluster V (10.353), cluster Ill and cluster IV (8.588),cluster I and cluster 11(8.038), cluster I and cluster IV (7.376) and so on. It is obvious that in most of the cases cluster IV produced the highest D2 values with all other clusters except cluster I. It revealed the wide diversity between them and the genotypes in these clusters could be used as parents in hybridization programme for getting maximum heterosis. These results were supported by the findings of Saini and Kaicke (1987). The minimum inter cluster divergence as observed between cluster I and cluster III indicating that the genotypes of these cluster was genetically closed. Clustering pattern was shown in Fig. 1.

Table 2. Intra (Bold) and inter cluster distance $\left(\mathrm{D}^{2}\right)$ for 36 restorer lines.

\begin{tabular}{c|c|c|c|c|c}
\hline Cluster & I & II & III & IV & V \\
\hline I & $\mathbf{0 . 1 8 2}$ & 8.038 & 2.885 & 7.376 & 4.359 \\
II & & $\mathbf{0 . 2 6 8}$ & 6.301 & 14.064 & 10.353 \\
III & & & $\mathbf{0 . 2 2 8}$ & 8.588 & 4.825 \\
IV & & & & $\mathbf{0 . 2 5 5}$ & 6.683 \\
V & & & & & $\mathbf{0 . 2 2 1}$ \\
\hline
\end{tabular}

The selection of diverge genotype from cluster would produce a broad spectrum of variability for morphological and quality traits studied which may enable further selection and improvement. The hybrid developed from the selected genotypes within the limits of compatibility of these clusters may produce high magnitude of heterosis. This would be rewarding in hybrid rice breeding programme. Sarawgi and Shrivastava (1996), Sarawgi and Rastogi (2000), Roy et al. (2002) and Naik et al. (2004) were in agreement with these findings. 


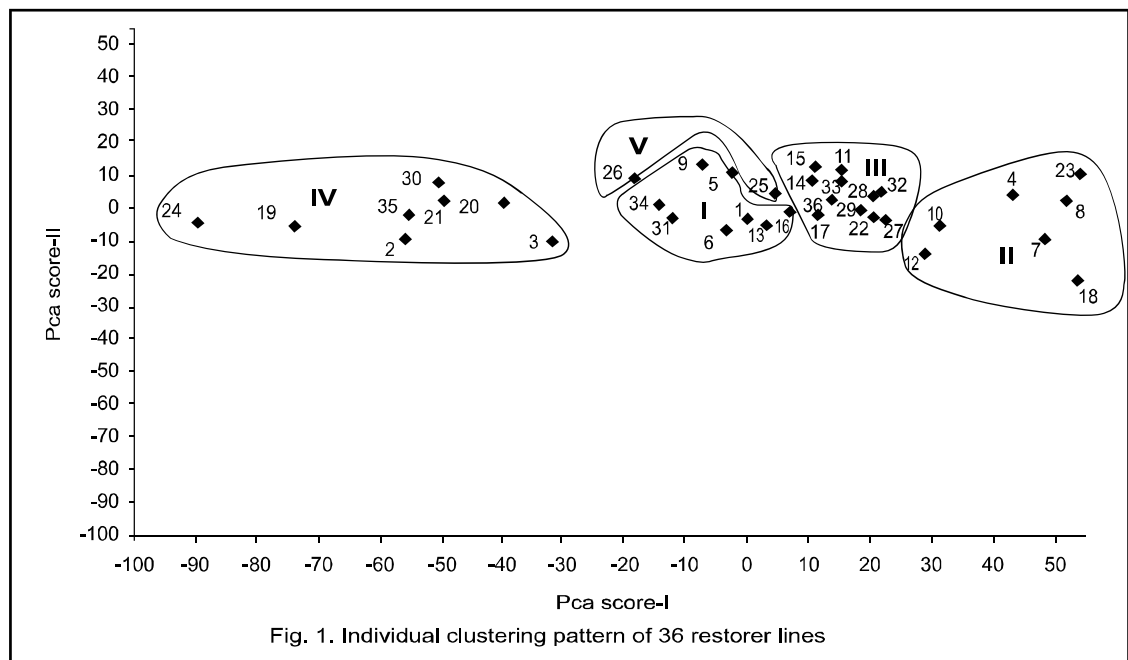

Cluster mean value of 9 different characters are shown in Table 3. Difference in cluster means existed for almost all the characters studied. The highest mean value for plant height $(\mathrm{cm})$, number of tillers/hill, panicle length $(\mathrm{cm})$, number of filled grains per panicle. spikelet fertility percentage, and grain yield/plant (g) was observed in cluster IV, that means the restorer line fallen in cluster IV having the potentiality to contribute better for yield maximization of hybrid rice. Cluster $\mathrm{V}$ possessed genotypes with days to $50 \%$ flowering, maturity and highest 1000 -grain weight, cluster II had the genotype that showed maximum days to $50 \%$ flowering and days to maturity, lowest yield contributing characters (number of tillers/hill, panicle length (cm), number of filled spikelets/panicle, spikelet fertility percentage) and yield/plant indicating selection of genotypes from this cluster for future hybrid rice breeding programme have no positive impact except for 1000-grain weight. Maximum 1000 grain weight was shown in cluster V (26.3 g), which is helpful for bold grain hybrid rice.

Table 3. Cluster mean values of nine different characters of $\mathbf{3 6}$ rertorer lines.

\begin{tabular}{l|cccccc}
\hline \multicolumn{1}{c|}{ Characters } & I & II & III & IV & V \\
\hline Days to 50\% flowering & 132.87 & 135 & 134.36 & 134.5 & 144 \\
Days to maturity & 158.25 & 162 & 161.09 & 161.37 & 167.5 \\
Plant height (cm) & 95.5 & 95.14 & 88.36 & 98.75 & 80.5 \\
No. of tillers/hill & 11.38 & 8.86 & 10.18 & 13.38 & 11.5 \\
Panicle length (cm) & 23.37 & 20.14 & 21.55 & 25.75 & 23.5 \\
No. of filled spikelets/panicle & 126.75 & 82 & 108.27 & 178.62 & 131 \\
Spilelet fertility \% & 85.87 & 67.29 & 79.55 & 92 & 87 \\
1000-grain weight (g) & 24.45 & 24.49 & 23.39 & 24.82 & 26.3 \\
Yield/plant (g) & 25.06 & 20.25 & 22.89 & 27.66 & 25.15 \\
\hline
\end{tabular}


Results of relative contribution towards divergence are presented in Table 4. Vector-I and Vector-2 value was obtained from PCA.

In first axis vector-I all the studied characters had negative impact towards divergence except for days to $50 \%$ flowering and days to maturity.

Table 4. Relative contributions of the nine characters of 36 restorer lines to the total divergence.

\begin{tabular}{lcc}
\hline \multicolumn{1}{c|}{ Character } & Vector-I & Vector-II \\
\hline Days to 50\% flowering & 0.0271 & -0.7011 \\
Days to maturity & 0.0348 & -0.7043 \\
Plant height (cm) & -0.1375 & -0.0648 \\
No. of tillers/hill & -0.4366 & 0.0256 \\
Panicle length (cm) & -0.4461 & -0.0489 \\
No. of filled spikelets/panicle & -0.446 & -0.0155 \\
Spilelet fertility & -0.4273 & 0.0166 \\
1000-grain wt (g) & -0.0984 & 0.0297 \\
Yield/plant (g) & -0.4453 & -0.0607 \\
\hline
\end{tabular}

In vector-2 number of tillers/hill, spikelet fertility percentage. 1000-grain weight had positive impact towards divergence (Hasan et al., 2010). Joshi and Dhawan (1966) reported that genetic diversity was very much important factor for any hybridization programme aiming at genetic improvement of yield, especially in self-pollinated crops. Bhatt (1970) inferred that Mahalanobis's D ${ }^{2}$ statistic was a powerful tool as a method of choosing parents for hybridization aiming at hybrid improvement.

Distribution of genotypes in clusters indicated that cluster III comprised of maximum number (eleven) of genotypes. The inter-cluster distance was maximum between clusters II and IV (14.064) indicating wide genetic diversity between these two clusters followed by the distance between cluster II and V (10.353), cluster III and cluster IV (8.588). The minimum inter-cluster distance was observed between cluster I and cluster III (2.885) followed by cluster I and cluster V (4.359) and cluster III and cluster V (4.825) indicating that the genotypes of these clusters were genetically close. However, considering the number of tillers/hill, number of spikelets/panicle, spikelet fertility \%, yield/plant cross involving genotypes of cluster IV and cluster 11 may exhibit high heterosis for yield. Similarly genotypes of cluster V might be crossed with the genotypes of cluster I for earliness. 


\section{References}

Annonymous. 2009. Bangladesh Arthanaitic Sarneekhkha, Ministry of Finance, Government of Bangladesh.

Anwer Faruque. 2009. Hybrid seed for food security. Keynote paper in the Bangladesh Seed Conference and Fair 2009 held at Bangladesh China Friendship Conference Centre during 28-30 May, 2009.

Bhatt, G. M. 1970. Multivariate analysis approach to selection of parents of hybridization aiming at yiald improvement of self-pollinated crops. Aust. J. Agric. Res. 21: 1-7.

De, RN. and A.V.S. Rao. 1987. Genetic divergence in rice under low land situation. Crop Improv. 14: 128-131.

Digby, P.N., Galway and P. Lane. 1989. Genstat 5: A second course. Oxford Sci. Publication, Oxford. pp 103-108:

Hasan, M. J., U. Kulsum. M. H. Rahman, A. Akter, and S. H. Bulbul. 2010. Diversity studies of 32 maintainer lines of hybrid rice ( Oryza saliva L.). Eco-friendly Agril. J. 3(3): 150-153.

lftekharuddaula, K. M., K. Akter, M. K. Bashar and M.R. Islam. 2002. Genetic parameters and cluster analysis of panicle traits in irrigated rice. Bangladesh J. P1. Breed Genet. 15(1): 49-55.

Jager, M. I., D. Garethojones and E. Griffith. 1983. Component of partial resistance of wheat seedlings to Septoria nodorum. Euphytica 32: 575-5 84.

Joshi, A. B. and N. L. Dhawan. 1966. Genetic improvement of yield with special reference to self-fertilizing crops. Indian J. Genet. P1. Breed. 26A: 101-113.

Julfiquar, A.W., S.S.Virmani and A.L. Carpena. 1985. Genetic divergence among some maintainer and restorer lines in relation to hybrid breeding in rice (Oryza saliva L.). Therory of Applied Genetics 70(6): 671-678.

Hossain, M. 1995. Sustaining food security for fragile environments in Asia: achievements, challenges and implications for rice research. In: Fragile lives in fragile ecosystems. Proceedings International Rice Research Conference, 13- 17 Feb. 1995, Manila. Philippines. International Rice Research Institute. p 3-23.

Mahalanobis, P. C. 1936. On the generalized distance in statistics. Proc. NatI. Inst. Sci. India, 2: 49-55.

Naik, A. R., D. Chaudhury and J. N. Reddy. 2004. Genetic divergence studies in scented rice. Oryza 40: 79-82.

Roy, B., A. K. Basu and A. B. Mandal. 2002. Genetic diversity in rice (Oryza saliva L.) genotypes under humid tropics of Andaman based on grain yield and seed charecters. Indian Journal of Agricultural Science 72: 84-87.

Saini, H. C. and U.S. Kaicke. 1987. Genetic diversity in opium poppy. Indian J. Genet 291-296.

Sarawgi. A. K. and M. N. Shrivastava. 1996. Genetic divergence in rice under irrigated and rainfed condition. Advances of Plant Science 9: 93-100. 
Sarawgi, A. K. And N. K. Rastogi, 2000. Genetic diversity in traditional aromatic rice accessions from Madhya Pradesh. Indian Journal of Plant Genetic Research 13: 138-146.

Singh,V. P., M.S. Swaminathan, B.R. Mchra and E.A. Siddiqui, 1979. Divergence among dwarfs of cultivated rice. Indian J. Genet. 39: 315-322.

Singh, R.S. 1981. Genetic divergence in indigenous varieties of rice grown in Mirzapur district. UP. India Int. Rice Res. Newsl. 6.3-4.

Singh, S. K., R. S. Singh, D. M. Maurya and 0. P. Verma. 1987. Genetic divergence among low land rice cultures. Indian J. Genet. 39: 315-322.

Yuan. L. P. 2001. Hybrid rice in China: Present status and future vision. Paper presented at BARC in the workshop on Development and Use of Hybrid Rice in Asia.

Virmani, S. S. 1994. Prospects of hybrid rice in the tropics and subtropics. In: Hybrid rice technology: New Development and Future Prospects (Ed.). S.S. Virmani, IRRI, Manila, Philippines, pp.7-19. 